\title{
Degree of Upper Basic Stage Mathematics Teachers' Use of Alternative Assessment Strategies and Its Tools in Al-Mafraq Governorate and Their Attitudes Towards Them
}

\author{
Awad Mufleh Shihab Alkhazam ${ }^{1, *}$ \\ ${ }^{1}$ Department of Curriculum and Instruction, Faculty of Educational Sciences, World Islamic \\ Sciences \& Education University, Amman, Jordan \\ *Correspondence: Department of Curriculum and Instruction, Faculty of Educational \\ Sciences, World Islamic Sciences \& Education University, P.O. Box 1101, Amman, Jordan. \\ Tel: 962-777-320-702.E-mail: awad_kaldy@yahoo.com
}

Received: March 28, 2017 Accepted: April 25, 2017 Published: June 20, 2017

doi:10.5296/ije.v9i2.11485 URL: http://dx.doi.org/10.5296/ije.v9i2.11485

\begin{abstract}
This study aims at identifying the degree of using alternative assessment strategies and its tools by the upper basic stage Math teachers in Mafraq Governorate and revealing their attitudes towards using these strategies. The sample of the study consisted of (180) Math teachers. The researcher adopted two questionnaire for collecting data; the first one consisted of (20) items including the alternative assessment and its tools while the other questionnaire consisted of (30) items addressing the Math teachers' attitudes towards using the alternative assessment and its tools. The study came up with the following the results: Math teachers' use of assessment strategies was moderate with a total mean (2.50) and Pencil and Paper strategy came first with a high degree followed respectively by observation strategy with moderate degree, performance based assessment strategy with moderate degree and reflection assessment strategy with low degree. Results also showed that the Math teachers' use of alternative assessment strategies and its tools was moderate with a mean (2.74) and the teachers' attitudes towards using these strategies were positive. The study recommended using alternative assessment strategies and its tools as one of the basic evaluative competencies of Mathematics teachers.
\end{abstract}

Keywords: alternative assessment strategies and its tools, teachers' attitudes, assessment of Math learning 


\section{Introduction}

Assessment has occupied a significant role in identifying to which degree the student succeed in achieving the goals and taking decisions concerning these goals as the first step for reforming and developing the education. The assessment is considered as an integrated part with the learning process rather than a complement. The assessment strategy helps in learning Mathematics and provides the students and the teachers with useful information. The process of assessment has many goals rather than recoding the student's grades; it guides and support the students' learning and treat their points of weakness. The effective assessment process could supply the students with formation about necessary patterns of knowledge and performance and this affects the students' decisions concerning their effort in studying. Moreover, the teachers' decisions in teaching will rely on what students know or what they need to know. Feedback which is a part of assessment helps in identifying students' goals, motivating them to be independent and responsible learners(NCTM, 2000).

The assessment strategy aims basically at improving the learning process. The effective assessment in the class helps in supporting teaching efficiency, in addition to guiding and counseling the students and exploring their needs, problems, abilities and attitudes. Furthermore, the assessment strategy helps the teacher to review and revise his teaching strategies used in the classes which will improve his teaching accordingly(Popham, 2002, P85).Assessment process which the teacher followed in conducting exams or in oral questions or observations to identify degree of success in achieving the curricula's goals does not cover all the aspects of the learner's mental growth and it ignores the diagnosis and treatment processes.

The teacher's continuous observation of the student's behavior aims to measure the learning outcomes which supposedly the student achieved in all the cognitive, emotional and motor fields. Means of assessment in Mathematics vary according to the goal's levels. The assessment means which are used to assess achievement are not the same that are used to measure attitudes and level (Abdhadi, 2001). Written tests are the math teachers' favorite method to assess their students or to measure learning outcomes in the cognitive field and they rarely use others methods although there are variety of learning situations that require using other methods of assessment. It was found that the written tests do not suit some learning outcomes and therefore the modern trends in assessment argue that tests is just one type out of many assessment types(Abo-Zeina,2003). Some studies showed that the tests which the teachers use to assess students do not take into account the relevant significance standard and these tests are mainly not prepared well (Thorndike, Hagen, 1989). The modern school does not only concentrate on the learners' cognitive aspect but it also pays attention to all aspects of the learner's growth since it believes in the integration and balance in the learner's character. And it is noted that the traditional tests focus on measuring the student's knowledge rather than his real performance or on assessment in virtual situations which affect checking the employment of performance and knowledge in real situations, or the direct performance of learning outcomes. In other words, assessment based tests is not enough to evaluate the learning process and thus collecting data using other means rather tests has great importance in assessment process(Oudah,2010). 
Ministry of Education in Jordan has developed comprehensively the learning process including curricula, tests and training. Additionally, the ministry sets a general frame for the curricula and assessment including the necessity to use variety of assessment strategies and its tools and not be limited to pencil and paper strategy (Ministry of Education, 2004).

The National Council of Teachers of Mathematics (NCTM) has started to reform Math at schools since 1989 with a slogan "Mathematics for all" which was based on evoking the learner's thoughts, developing his thinking skills, increasing his ability for learning and improving the ability of forming the relations, the council sets basic principles for teaching and learning Math concerning assessment including: assessment document in 1995 and assessment principle in 2000. Bush \&Greer(1999) claim that there are reasons necessitate changes in assessment techniques; many students believe that assessment is different from education as they considered it a series of separated events which are unrelated to what they learn daily in the class. Additionally, the learners are not involved and integrated in the assessment process and they are not given any chance to show their creativity.

Trice (2000) thinks assessment has different patterns depending of the teachers' goals of teaching and the students' age, their ability and the teacher's philosophy. These patterns include the teacher's notes which he collected during his daily work with the students, or his following up the classes activities and assignments and the exam is one of assessment's patterns.

Individual and group interviews are alternative assessment methods in Math and they can show the learners' abilities, skills and learning. In organizing these interviews, the teacher has to prepare in advance the tasks which the students; in groups or individually do in Math and the teacher needs to make his notes using different means as reviewing list and descriptive rating checklist(Agl,2001). Portfolios are considered one of the assessment tools that allow the students to employ their knowledge and skills in doing extended tasks in Math, and individual and group authentic projects. These portfolios may contain Math research that require collecting data and analyzing them and coming up with results and interpretation. The students' involvement in such activities develops their thinking skills and solves situational problems in addition to help them to review their work and learn the constructive self criticism and evaluate others' work (Alam, 2004).

Therefore, there is a need to vary the assessment methods which the teachers use to measure the students' outcome learning to suit the methods and curricula of teaching Math which the National Council of Teachers of Mathematics (NCTM) has issued.

Alternative assessment strategies and its tools:

1. Performance-based Assessment: this strategy is based on measuring the learner's ability to use the skills which has learned in real life situations. This strategy includes the following assessment situations:

a. Presentation: it is an organized and planned show done by the learner or a set of learners discussing a specific topic within a specific date so as to reveal their 
possession of some skills. For example, the learner explains a specific issue using images, pictures and slides,...etc.

b. Demonstration: it is an oral or verbal presentation done by a learner or set of learners to show their ability of representing the issue or the concept with more appropriate way. For example, clarifying a concept through conducting an experiment or linking it with real life situation.

c. Performance: it is a set of procedures to present knowledge, skills or attitudes through specific tasks done by the learner. For instance, the learner designs a map, or a model, or a tool, or an engine, or prepare kind of sweet.

d. Speech: a learner or more talk about specific issue with limited time. This talk could be telling a story, summarizing a novel and linking ideas, and describing a journey or a movie.

e. Exhibition: the learners presented their cognitive and practical product within a specific time and place showing their capability in employing their skills in a specific field to achieve specific goals. For example, the learner cans presents models, or pictures, or paintings, or works of art, or products, or handicrafts.

f. Simulation\ Role-playing: the learner or the learners discuss an issue simulating real life situations to show their cognitive and acting skills and their ability to follow regulations, communication and to present suggestions in addition to make decisions and solve problems. These situations could be technically programmed where the learner is integrated in a computerized simulated situation and therefore the learner has to do the same tasks and make the same decisions that are possible to happen in the future (Al-Najar, 2010).

2. Pencil and Paper strategy: it is one of the most important strategies used to measure the learner's skills and abilities in specific fields and it is considered an important part in the school's evaluation program.

3. Observation strategy: it is the teacher's use of his senses to monitor the learner's reaction in an active situation so as to get beneficial information about the learners which facilitate judging the learner's performance, his skills, values, behaviors, ethics and methods of thinking. This strategy includes systematic and unsystematic observation (Alam, 2010).

4. Communication strategy: gathering information through communication activities to investigate the learner's progress and identify his ways of thinking and solving problems. This strategy includes the following situations:

a- Interview: it is a meeting between the teacher and the students identified previously that helps the teacher to obtain information about the learner's thoughts and attitudes towards a specific subject and it includes a set of prepared questions in advance. 
b- Questions and answers: they are the teacher's direct questions to the student to check his progress, collect information about his thought and problem solving methods but these questions do not need any preparation in advance.

c- Conference: it is a programmed meeting between the teacher and the learner to assess the learner's progress in a specific project to a specific date through the discussion which is followed by identifying the steps that should be followed later to improve his learning.

d- Reflection strategy: This strategy shows the extent of the learner's cognitive growth and it is a basic component of the effective self learning. It includes self evaluation, student's journal, and student's portfolio. This strategy includes the following:

a- Self evaluation: the learner himself assesses his learning after finishing a specific activity and judges his performance through a model prepared by the teacher to achieve the outcomes.

b- Portfolio: it is a tool used to help the students assess their learning and it is a collection of students' samples of students' work chosen carefully to show progress over time. The student needs to participate in selecting the samples which will be kept in his portfolio because this will helpful for the students to assess each model or work and to mention causes of rejection of a model. The student's portfolio is an evidence of his progress over time showing points of weakness and strength. The student, the teacher and the parents can review the portfolio and discuss it with the students looking for the following steps. As a result the students become more responsible for their learning witnessing their success over time.

c- Response Journal: it could be used for many subjects where students can write their thoughts about what they see and read. It records their notes and interpretations. Journal motivates creative thinking. It helps the teacher to know the students' points of weakness and strength and to guide them towards the right direction. The student is involved in the process of his assessment and progress and the teacher is gives the student's different opportunities to express their views in a good academic manner so as to improve his performance and be more aware of his work and progress. This strategy is just like a mirror that reflects the person's experiences, impressions, ideas and successes in addition to his points of weakness and strength. It helps the teacher to make the appropriate decisions concerning coming steps and to determine nature of counseling. On the other hand, the student himself can recognize his capabilities and criticize himself. This strategy helps opening channels for dialogue, discussion, creative .human and academic communication between the learner and the teacher (Jaber, 2010).

\subsection{The Alternative Assessment Tools}

1- Rubric: it is one of the assessment strategies that consist of a series of words and adjectives that describe the learner's performance in different levels. It is more detailed than rating scale with verbal description. It helps the student to determine his coming step towards improvement. 


\section{Macrothink}

2- Learning Log: it is an organized record where the learner writes freely expressions, notes and views about things he saw, read or passed by in his personal life.

3- Anecdotal Records: it is a short description of the learner's actions by the teacher. For example, the teacher can write the most important notes about the student's verbal and physical behavior within groups (cooperative work). The teacher has to record the learner's behavior on special cards highlighting place, time and doer of the activity of the behavior in addition to his personal comments (Oudah, 2010).

4- Check list: it is a list of actions recorded by the student or the teacher during the implementation of specific skill or mission, or it is a list of characteristics recorded by the teacher or the teacher during the observation process. The teacher or the student prepared the check list. It is possible to have a check list consisting of steps that should be followed by students to complete a project or it could be a set of skills, or concepts, or practices, or attitudes (Ministry of Education, 2004).

5- Rating scale: it is a simple tool to find out if the student's skills are low or high showing the degree that helps in observing skills, concepts, information and behaviors. This tool is used to judge level of the performance quality. Three point rating scale, according to the teacher, could be effective for the learner just like the five or ten point scale, it is important to remember that the students should share the teacher in setting the criteria and the scale has to show the development of the students' concepts and skills(Ministry of Education).

6- Portfolio: it is a focused accumulation of the learner's work and performance in a file or portfolio called the organized collection of the student's work to show his effort, progress and achievement. The portfolio is a tool of assessment has different types of assessment that use variety of measurement tools; written, official and free. This file provides images and evidences of the learner's progress over time and it may contain self assessment done by the learner himself. The portfolio contains works that proved the student's learning revealing what the student can do in a specific school subject, clarifying his achievement and progress which in turn reflects the philosophy of the school curricula (Alam, 2004).

7- Journals: this tool helps the student to employ what he learnt theoretically or to feel it in real life situations in addition to document situations that make a link between theory and application. For example, the student may link between what he learnt in lower basic stage and the clock and then relation starts to develop by student's written notes about the function of the clock and so the student transfers from one level to another (Oudah, 2005).

8- Socio-meters: they are tool used to judge the strength of a relation through individuals' attitudes towards each other and their desire to work cooperatively (Oudah, 2005).

9- Interview: it is a preferable method in collecting data in some situations as identifying the student's personal traits and characteristics that can employed in counseling and 
guidance processes. The written tests are considered as a form of an interview that is mainly used in the lower stage and in some specific subjects. Interview helps in correcting data when the students are incapable to write (Alam, 2010).

\subsection{Problem \&Questions of the Study}

Many teachers believe that the traditional assessment based on tests is the only assessment tool used to assess the students' achievement and this totally common among the teachers in all grades in all stages. The focus is on the lower cognitive levels ignoring the upper ones while the modern school does not only focus on the student's cognitive aspect but also it pays much attention to his all aspects of growth caring more about the integration and balance in the students' personality. Furthermore, learning outcome in the emotional side cannot be measured by written tests and so there is a need to have other assessment tools as observation or interview(Oudah, 2010). The accelerated steps in reforming education assured the necessity to make a shift to the methods and tools of assessment that give more clear and comprehensive image on the student's thinking, skills and his application of the knowledge and thus the image will be more realistic and holistic(Alam,2004). Based on what has been stated previously, the questions of the study were as follows:

1- What is the degree of Mathematics teachers' use of the alternative assessment strategies in the upper basic stage?

2- What is the degree of Mathematics teachers' use of the alternative assessment tools in the upper basic stage?

3- What are the attitudes of Mathematics teachers of upper basic stage towards the alternative assessment strategies and its tools?

\subsection{Significance of the Study}

The study is beneficial to the Mathematics teachers as it introduces the most important alternative assessment strategies and its tools and the employment of these strategies and its reflection on the students' performance and achievement. Additionally, it helps in changing the educational concepts concerning the alternative assessment and its tools for the teachers, students and parents and it provides exams and training department in Ministry of Education with a clear image about the status of the Mathematics' teachers' use of the assessment strategies and its tools so as to organize training course based on the teachers' needs.

\subsection{Limitations of the Study}

1. The study is limited to Math teachers of the upper basic stage (seventh till tenth grades) in the governorate schools in the directorates of education in Mafraq Governorate.

2. The study is implemented in the first semester of scholastic year 2016/2017.

3. The study adopted the following alternative assessment strategies (Pencil \&paper, observation, communication, reflection, performance based assessment), which limited by Ministry of Education in Jordan. (Ministry of Education in Jordan, 2004) 


\section{MInstitute Macrothink}

4. The study adopted the following alternative assessment tools (rating scales, check lists, learning log, Anecdotal Record) which were confirmed by Ministry of Education in Jordan. (Ministry of Education in Jordan, 2004).

\subsection{Terms of the Study}

Alternative Assessment strategies: they are the strategies which Ministry of Education in Jordan adopted to evaluate the students' performance including performance based assessment, pencil and paper, observation and communication.

Alternative assessment tools: they are the tools which the Ministry of Education in Jordan adopted to evaluate the students' performance including rating scale, check list, rubric, learning $\log$.

Degree of use: it is the degree of real use of the alternative assessment strategies and its tools by the Math teachers of upper basic stage in Mafraq Governorate and it is measured through the teachers' responses on the questionnaire's items.

Math teachers: they are the male and female teachers who teach Mathematics subject from the seventh grade till the tenth grade in the public schools in the three directorate of Education in Mafraq Governorate and who got BA degree in Math at least.

Attitudes towards using alternative assessment strategies and its tools: it is the feeling of the teachers towards using alternative assessment strategies and its tools in the learning process.

The upper basic stage: an educational stage starts from the seventh grade till the tenth grade according to the education system in Jordan.

\section{Previous Studies}

Qiannaqelo (2001) conducted a study aimed to reveal the perspectives of the Math teachers of the secondary stage in the Christian schools in USA concerning the efficiency of the alternative assessment in the academic achievement. The sample of the study consisted of (163) teachers. The researcher checks the sample's perspectives and analyzes their roles. The study showed positive perspective towards using the alternative assessment strategies and its tools.

The study of Alana (2007) aimed at identifying the sciences teachers' degree of practicing alternative assessment methods in teaching sciences of the $8^{\text {th }}$ basic grade in Jordan and the problems facing this practice. The sample of the study consisted of 16 male and female teachers representing $25 \%$ of the population of the study. Results revealed that the sciences teachers' practice degree of the alternative assessment methods in teaching sciences was moderate. There were statistical significant differences in the teachers' degree of practicing the alternative assessment methods attributed to the experience variable in favor of the teachers with more than ten years experience and the scientific qualification variable in favor of BA degree holders. 
In his study, Hiajnah (2007) soak to identify the extent to which the Arabic teachers use the alternative assessment strategies and the effect of a training program in practicing these strategies. The sample of the study consisted of (30) male and female secondary stage teachers in Irbid First directorate of Education. The researcher used the observation card as a tool for collecting data. Results showed that the degree of Arabic teachers' use of the alternative assessment strategies was moderate and there were statistical significant difference in the teachers' use of the alternative assessment attributed to the experience variable in favor of teachers whose experiences ranged from 1 to 10 years.

Al- rashidi's study (2008) aimed to measure the perspectives of the sciences teachers of the primary stage in State of Kuwait towards the alternative assessment strategies and their practice in the classroom. The sample of the study consisted of two groups; the first consisted of (120) male and female sciences teachers in the public primary schools in State of Kuwait for the year 2007-2008 while the other group consisted of (15\% )of the first group whose practice of the strategies was observed. Results revealed weak and insignificant correlation between the teachers' perspectives and the degree of their practice of the alternative assessment strategies in the classroom.

In the same context, Jameel (2009) conducted a study aimed at investigating the effect of using alternative assessment methods in the achievement of the tenth grade students in National Education Course and their attitudes towards them. A purposeful sample consisted of (172) students were chosen form Rosaifa Directorate of Education. Results showed statistical significant differences in the students' achievement in favor of the experimental group which was evaluated according to alternative assessment methods but there were no statistical significant differences in the tenth grade students' attitudes towards National Education course attributed to assessment methods.

The study of Nur, faradill \& et al (2010) aimed at identifying the teachers' perspectives towards using alternative assessment. The sample of the study consisted of 50 male and female secondary teachers in Brunei. A questionnaire was designed and distributed to the sample. Results revealed the teachers' positive perspective towards alternative assessment but their paper work increased.

In 2010, Abo-Haj conducted a study aimed reveal the degree of English teachers' knowledge of the alternative assessment methods and their use of them in the public and UNOWARA schools in Amman Governorate. The sample of the study consisted of (150) male and female teachers. Results showed the degree of English teachers' knowledge of the alternative assessment methods was high and there was positive correlation between their knowledge and their use of them.

Afanah's study (2011) aimed to identify the status of the Arabic teachers' use of the alternative assessment strategies in the UNOWRA schools at Gaza. The sample of the study consisted of 60 male and female teachers and 24 managers and supervisors. The researcher used a questionnaire and observations card as tools for collecting information. Results revealed that the written exams strategy came first followed respectively by observation, reflection, performance based assessment, peers, and performance based concept mapping, 
interviews and portfolio.

Al-aythem's study (2012) aimed to identify the extent to which the Arabic teachers of the primary stage use the alternative assessment strategies. The sample consisted of 27 female teachers. The researcher used the observation card as a tool for collecting data. Results showed high degree of weakness in the teachers' practice of alternative assessment skills except "question and answer skill" which its degree was moderate.

Avo Hashim, et al (2014) conducted a study aimed at identifying the skills of the Saudi sciences and Math teachers of the moderate stage concerning the assessment methods. A simple random sample consisted of 196 male and female teachers were chosen. The study's tool was the questionnaire which was prepared by the researcher to measure the sample' skills in using the alternative assessment methods. Results revealed that the most important and common skills used were the written exams, concept mapping and portfolio.

In his study (2015), Bani Oudah soaks to investigate the effect of using the alternative assessment in the ninth grade students' achievement and their attitudes towards sciences in the schools of Nablus Governorate. The cluster sample of the study which consisted of 102 ninth grade students was distributed to two equal groups; experimental (alternative assessment tools) and control (traditional assessment).

The researcher used achievement test, rating scale and a questionnaire to measure students' attitudes towards the sciences. Results showed the experimental group's superiority over the control group in achievement. Results also revealed lack of statistically significant differences between the groups in the achievement attributed to gender variable in addition to lack of statistical significant differences between the groups' attitudes towards the sciences.

Based on the previous studies, it is noted that the teachers' use of the alternative assessment strategies and its tools has great effect on improving learning outcomes but the teachers' degree of using them is still not at the required level. Most of the studies' samples were teachers who tend to use the traditional assessment base on written exams and this was assured by the studies of Al-Aythem(2012), Abohasim (2014),Afanah(2011) and Alhaijna (2007). The previous studies revealed lack of studies addressed Mathematics which is considered one of this study's advantages.

\section{Methodology \& Procedures of the Study}

The researcher adopted the survey and descriptive approach through designing and distributing two questionnaires to measure the teachers' use of alternative assessment strategies and its tools and to measure the teachers' attitudes towards using these strategies.

\subsection{Population of the Study}

The population of the study which consisted of all the Math teachers of the upper basic stage in the three directorate of Education in Mafraq Governorate was (360) male and female teachers as it is illustrated in table 1. 
Table 1. Distribution of the population of the study according to the directorate variable

\begin{tabular}{lc}
\hline \multicolumn{1}{c}{ Directorate } & N \\
\hline Al-Mafraq Educational Directorate in Al-Casaba District & 132 \\
North West Badia Directorate of Education & 120 \\
North East Badia Directorate of Education & 108 \\
Total & $\mathbf{3 6 0}$ \\
\hline
\end{tabular}

\subsection{Sample of the Study}

The sample which was selected randomly consisted of 180 male and female teachers representing $50 \%$ of the population of the study and the following table showed distribution of the sample according to the directorate and specialization variables.

Table 2. Sample's Distribution According to the Directorate Variable

\begin{tabular}{lc}
\hline Directorate & N \\
\hline Al-Mafraq Educational Directorate in & 66 \\
Al-Qasabah District & \\
North West Badia Directorate of Education & 60 \\
North East Badia Directorate of Education & 54 \\
\hline Total & 180 \\
\hline
\end{tabular}

\subsection{Tool of the Study}

After reviewing the theoretical literature and previous studies concerning the alternative assessment, the researcher built two tools represented by two questionnaires; the first one to measure the math teachers' use of assessment strategies and its tools while the second is used to measure the math teachers' attitudes towards using the assessment strategies and its tools. The first questionnaire consisted of the following assessment tools: Pencil and Paper, Communication, observation, Assessment Based Performance, and reflection and the others tools of assessment were: Check List, rating scales, Rubric, learning log and Anecdotal Record._An integrated scale was adopted (very high degree, high degree, moderate degree, low degree, very low degree)

There were (24) items reflecting the assessment strategies and its tools in its first draft. The tool's validity was checked by presenting it to a set of specialized arbitrators whose notes were taken into account and so the items were (20) items in the final draft. Whereas the second questionnaire consisted of (30) items measuring the teachers' attitudes towards their use of the assessment strategies and its tools. The reliability of both questionnaires was checked using Cronbah Alpha to measure the internal consistency of their items and it was for both tools (0.88) and his internal coefficient is considered acceptable for the educational studies. 


\section{Ml Macrothink}

\subsection{Variables of the Study}

The study has one independent variable which is the teacher's major (Math). The study has two dependent variables; the teachers' use of the alternative assessment strategies and its tools while the other was the teachers' attitudes towards their use of the assessment strategies and its tools.

\subsection{Statistical Treatment}

To answer the study's questions, means and standard deviations of the sample's performance were calculated. And to identify the degree of use, the researcher adopted the following criteria:

$$
1.33=\frac{5-1}{3}=\frac{\text { Maximum limit }- \text { minimum limit }}{N \text { of categories }}
$$

(1- 2.33) low degree

$(2.34-3.67)$ moderate degree

(3.68 - 5) high degree

\section{Results \& Discussion \& Recommendations}

\subsection{Results and Discussion Concerning the First Question}

What is the degree of upper basic stage Mathematics teachers' using of the alternative assessment strategies and its tools?

To answer this question, means and standard deviations were calculated as it is illustrated in table 3 .

Table 3. Means and standard deviations of the sample's responses on the alternative assessment strategies arranged ascending.

\begin{tabular}{cclccc}
\hline Rank & $\mathrm{N}$ & Alternative assessment strategies & $\mathrm{M}$ & Std & Degree \\
\hline 1 & 2 & Pencil and paper & 3.71 & 0.76 & High \\
2 & 3 & Observation & 2.46 & 0.82 & Moderate \\
3 & 1 & Performance based assessment & 2.40 & 1.03 & Moderate \\
4 & 4 & Communication & 2.37 & 1.032 & Moderate \\
5 & 5 & Reflection & 1.55 & 1.01 & Low \\
\hline \multicolumn{7}{l}{ Total degree } & 2.50 & 0.85 & Moderate \\
\hline
\end{tabular}

The previous table showed that the degree of Math teachers' use of the alternative assessment strategies was moderate with total mean (2.50) and standard deviation (0.85). Also, the table showed that pencil and paper strategy came first with a mean (3.71) and standard deviation 
(0.76) with a high degree followed respectively by: Observation Strategy (2.46-0.82) with a moderate degree, the performance based assessment strategy (2.40) - 1.03) with moderate degree, the communication strategy $(2.37-1.032)$ with low degree and the reflection strategy (1.55- 1.01) with a low degree.

To conclude the table showed that the Math teachers of the upper basic stage use the pencil and paper strategy with a high degree and this may due to the ease of using this strategy and its accuracy in judging the students' performance. The researcher also attributed this result to the nature of the Math course which focuses on the cognitive aspect which could be easily measured by the daily and monthly exams. Additionally, such result may due to the type of assessment the teacher himself used to know while he was a student in the school and the university.

Concerning the use of observation strategy which came second with a moderate degree, the researcher attributed this result to the teachers' interest in observing the students and checks their performance and behavior using organized checklist prepared for this purpose. Results showed also that assessment based performance came third with moderate degree and this may due to the strategy's activities represented by presentation, practical application, playing roles, simulation and others that attract the students' attention. Additionally, results showed that the communication strategy came in fourth rank with moderate degree. The teachers use this strategy through interviewing the students and communicating with them to study their academic weakness and sets remedy plans.

And regarding the reflection strategy, results showed their low degree and this my due to the difficulty facing implementation such type of assessment as it may need specific tools and ongoing assessment, or it may due to the strategy's strong relation with the psychomotor Objectives, or it may attribute to the teachers' lack of belief of the benefit of using this strategy in assessing the students' performance or their inability to apply it in classroom situations.

This result is in compatible with the result of the studies of Alana (2007) and Haiajna (2007) but it disagrees with the study of Abo-Haj (2010) which concluded that the degree of English teachers' use of alternative assessment strategies was high and the study of Alythem (2012) which revealed the Arabic teachers' weak degree in their use of the alternative assessment strategies and skills.

\subsection{Results and Discussion Concerning the Second Question}

What is the degree of the Math teachers of the upper basic stage of the alternative assessment tools?

To answer this question, means and standard deviations were calculated as it is illustrated in table 4. 


\section{MInstitute Macrothink $^{m}$}

Table 4. Means and standard deviations of the sample's responses arranged ascending.

\begin{tabular}{|c|c|c|c|c|c|}
\hline Rank & $\mathrm{N}$ & Alternative assessment tools & M & Std & Degree \\
\hline 1 & 2 & I use the rating scale to judge the students' performance & 3.75 & 0.78 & High \\
\hline 2 & 1 & I use check list as a tool of assessment & 3.54 & 1.05 & Moderate \\
\hline 3 & 3 & $\begin{array}{l}\text { I employ rating scale in assessment as a tool of } \\
\text { assessment. }\end{array}$ & 2.88 & 1.00 & Mod \\
\hline 4 & 5 & $\begin{array}{l}\text { I rely on learning log to describe the student's actions } \\
\text { and behavior. }\end{array}$ & 2.17 & 1.52 & Low \\
\hline 5 & 4 & $\begin{array}{l}\text { I activate anecdotal record as one of the assessment tools } \\
\text { in following up the students behavior }\end{array}$ & 1.36 & 1.16 & Low \\
\hline & & Total degree & 2.74 & .99 & Moderate \\
\hline
\end{tabular}

It is noted from the previous table that the degree of the teachers' practice of the alternative assessment tools was moderate with total mean (2.74) and standard deviation (0.99). the item "I use the rating scale to judge the students' performance" came first with a mean(3.75) and standard deviation(1.37)and with a high degree followed by item "I use check list as a tool of assessment" with a mean(3.54) and standard deviation(1.05) with a moderate degree, whereas item "I activate anecdotal record as one of the assessment tools in following up the students behavior" with a mean(1.36) and standard deviation (1.16) with a low degree.

Based on these results, it is clear that the most common tool used by the teachers was rating scale and this may due to its advantages in facilitating the process of assessment, saving the teacher's effort and time. Furthermore, it is an objective tool.

The other tools used respectively by the teachers were: checking lists (Yes/No) because they could be prepared and corrected easily and they are considered an effective tool to get information that help the teacher to identify the student's points of weakness and strength in his performance, Rubric scale for being more complicated to be prepared and used, Learning $\log$ and anecdotal record came last with low degree. This result may attribute to the teachers' lack of awareness of the importance of these two tools in the assessment process or lack of ability to employ or prepare them for the difficulty of estimating its degrees and transfer them to numbers.

\subsection{Results and Discussion Concerning the Third Question}

What are the math teachers' attitudes towards using the alternative assessment strategies and its tools?

To answer this question, Means and Standard Deviations were calculated as it is illustrated in table 5 . 


\section{MInstitute ${ }^{\text {Macrothink }}$}

Table 5. Means and standard deviations of the sample's responses arranged ascending

\begin{tabular}{|c|c|c|c|c|c|}
\hline Rank & $\mathrm{N}$ & Items & $\mathrm{M}$ & Std & Degree \\
\hline 1 & 6 & $\begin{array}{l}\text { using alternative assessment strategies and its tools to } \\
\text { measure different aspects of the learner's personality }\end{array}$ & 3.92 & 1.118 & Big \\
\hline 2 & 4 & $\begin{array}{l}\text { Using alternative assessment and its tools to describe } \\
\text { the students' actual progress towards achieving the } \\
\text { goals }\end{array}$ & 3.84 & 1.037 & Big \\
\hline 3 & 1 & $\begin{array}{l}\text { The student's achievement seems better when } \\
\text { alternative assessment strategies and its tools are used } \\
\text { compared to the traditional strategies(written exams) }\end{array}$ & 3.83 & 1.211 & Big \\
\hline 4 & 8 & $\begin{array}{l}\text { Using alternative assessment strategies and its tools is } \\
\text { not imposed by the ministry. }\end{array}$ & 3.83 & 0.998 & Big \\
\hline 5 & 12 & $\begin{array}{l}\text { Using alternative assessment strategies and its tools } \\
\text { develops high mental skills. }\end{array}$ & 3.81 & 1.083 & Big \\
\hline 6 & 15 & $\begin{array}{l}\text { Using alternative assessment strategies and its tools } \\
\text { develops students' daily skills. }\end{array}$ & 3.75 & 1.105 & Big \\
\hline 7 & 9 & $\begin{array}{l}\text { There is a motivation from school management and the } \\
\text { ministry to use alternative assessment strategies and its } \\
\text { tools. }\end{array}$ & 3.69 & 1.034 & Big \\
\hline 8 & 5 & $\begin{array}{l}\text { I prefer using alternative assessment strategies and its } \\
\text { tools. }\end{array}$ & 3.67 & .976 & Big \\
\hline 9 & 10 & $\begin{array}{l}\text { Using alternative assessment strategies and its tools } \\
\text { enhance students' self evaluation. }\end{array}$ & 3.64 & 1.236 & Big \\
\hline 10 & 2 & $\begin{array}{l}\text { Using alternative assessment strategies and its tools } \\
\text { develops thinking and problem solving skills. }\end{array}$ & 3.64 & 1.055 & Big \\
\hline 11 & 16 & $\begin{array}{l}\text { Using alternative assessment strategies and its tools } \\
\text { presents feedback to the teacher about the } \\
\text { effectiveness of the teaching methods he used. }\end{array}$ & 3.55 & 1.236 & Big \\
\hline 12 & 7 & $\begin{array}{l}\text { Using alternative assessment strategies and its tools } \\
\text { presents to the feedback about the degree of his } \\
\text { success in achieving the goals. }\end{array}$ & 3.51 & 1.087 & Big \\
\hline 13 & 25 & $\begin{array}{l}\text { I join my students in identifying the criteria of the tool } \\
\text { used in the alternative assessment strategies. }\end{array}$ & 3.15 & 1.009 & Big \\
\hline 14 & 20 & $\begin{array}{l}\text { Using alternative assessment strategies and its tools } \\
\text { helps students to acquire communication skills. }\end{array}$ & 3.47 & .977 & Big \\
\hline 15 & 18 & $\begin{array}{l}\text { It is possible to use alternative assessment strategies } \\
\text { and its tools to assess high goals' levels (analysis, } \\
\text { creativity). }\end{array}$ & 3.45 & 1.075 & Moderate \\
\hline 16 & 27 & $\begin{array}{l}\text { I encourage using alternative assessment strategies and } \\
\text { its tools for they enrich assessment process. }\end{array}$ & 3.42 & 1.031 & Moderate \\
\hline 17 & 11 & $\begin{array}{l}\text { Alternative assessment strategies and its tools are easy } \\
\text { to use compared to the written assessment for the } \\
\text { teacher. }\end{array}$ & 3.41 & 1.030 & Moderate \\
\hline
\end{tabular}


1824 Using alternative assessment strategies and its tools activates students' role in the class.

1913 Using alternative assessment strategies and its tools activates the teacher's role in teaching process.

2029 Using alternative assessment strategies and its tools

$3.32 \quad 1.194$ Moderate presents detailed information about the students when school management or the parents ask about.

213 I think using alternative assessment strategies and its tools is more accurate in assessing the students' performance.

2228 Using alternative assessment strategies and its tools is fairer than other means of assessment.

2326 I use alternative assessment strategies and its tools because they focus on all aspects of learning and its outcomes.

2421 Using alternative assessment strategies and its tools helps the teacher to control his students.

2514 Using alternative assessment strategies and its tools gives the teacher more space in recording student's grades.

$2630 \quad$ I like to participate in training courses that help me to learn how to use alternative assessment strategies and its tools.

2723 I face difficulty in preparing alternative assessment strategies and its tools.

2819 I do not prefer using alternative assessment strategies and its tools in the class.

$29 \quad 17$ I hate using alternative assessment strategies and its tools because they are waste of time and effort for the teacher.

$30 \quad 22$ I think using alternative assessment strategies and its tools are ineffective in evaluation process

$3.38 \quad 1.033 \quad$ Moderate

$3.35 \quad 1.365$ Moderate

3.32 .993 Moderate

$3.30 \quad 1.045$ Moderate

$3.29 \quad 1.242$ Moderate

$3.27 \quad 1.078$ Moderate

3.251 .149 Moderate

3.221 .091 Moderate

3.191 .019 Moderate

3.17 1.219 Moderate

3.150 .958 Moderate

Total degree

$2.84 \quad 1.334$ Moderate $3.36 \quad 0.550 \quad$ Moderate

The previous table showed the means of the sample's attitudes towards using the alternatives assessment strategies and its tools ranged (from 2.84 to 3.92) and the item with the highest mean was "using alternative assessment strategies and its tools to measure different aspects of the learner's personality" while the item with the least mean was "I think using alternative assessment strategies and its tools are ineffective in evaluation process". It is clear that most items' means were higher than (3.00) with a total mean for the whole field(3.36) which revealed the teachers' positive attitudes towards using the alternative assessment strategies and tools and this result agrees with the result of the study of Nur, Faradill et al(2010). The 
researcher attributed this result to the Math teachers' awareness of the importance of using the alternative assessment strategies and its tools in the evaluation process and to the training courses which Ministry of Education organized to highlight the significance of using this type of assessment and the necessity of using different assessment tools and strategies.

\subsection{Recommendations}

1- The necessity to train Mathematics teachers in the upper basic stage on using the alternative assessment strategies (communication\& reflection) and assessment tools (learning log, Anecdotal Record) and activate them in the process of assessing the students learning.

2- The necessity to consider using assessment strategies and its tools as the evaluation competencies of Mathematic teachers.

\section{References}

Abdhadi, N. (2001). Measurement and Assessment and Its Use in Class Room Teaching. Amman, Dar Wael, p:472.

Abo hashim, et al. (2014). Saudi Mathematics and Sciences Teachers' Skills and Knowledge About Methods of Assessment. International journal of Educational Research, 35.

AboZeina, F, K. (2003). School Mathematics Curricula and Teaching Them, Alfalah for Publishing and Distribution, Kuwait: Kuwait, p: 339.

AboHaj, A. (2010). The Extent of Knowledge and Use of alternative Assessment Techniques Among Upper Basic Grades English Language Teachers in the Capital Amman. Unpublished Dissertation, Amman, Jordan.

Afanah, M, A. (2011). Status of Arabic teachers' use in the preparatory stage of assessment methods in the schools of UNOWRA in Gaza district in light of modern trends. Unpublished thesis, Islamic University, Gaza, Palestine.

Alam, S, M. (2004). Alternative education assessment: theoretical and methodological basics and its field applications. Dar Fikr Arabi, p: 176.

Alam, S, M. (2015). Measurement and assessment in teaching process. Dar Almasera for distribution and publishing, Amman, Jordan, p:157

Alawnah, H, I. (2007). Sciences teachers' practices of alternative assessment tools in teaching science of the $8^{\text {th }}$ grade in Jordan and problems facing these practices, Unpublished thesis, Yarmouk University, Irbid, Jordan.

Alaythem, N, A. (2012). Extent of Arabic teachers' use of alternative assessment tools in the primary stage, unpublished thesis, University of Mohammad Bin Saud, Saudi Arabia.

Al-Najar, N, J. (2010). Measurement and assessment; application perspective with SPSS application, Dar Hamed for publishing and distribution, Amman, Jordan, p:140. 
Al-rashidi, A, A. (2008). Perceptions of science teachers of primary stage at Kuwait of the alternative assessment strategies and its tools and their practice of them, Unpublished thesis, University of Jordan, Amman, Jordan.

Aql, A. (2001). Towards better Assessment, Beirut: Dar Nahda for publishing and distribution.

Bani Oudah, K, R. (2015). Effect of alternative assessment in ninth graders' achievement and attitudes towards sciences in Nablus Governorate school, unpublished thesis, Al-Najah National University, Palestine.

Bush, W., \& Greer, A. (1999). Mathematics assessment: a practical hand book for grades 9-12. Va: National council of teachers of mathematics.

Gianna Gelo, D. (2001). The perception of Secondary Mathematics Teacher in Christian School on the Effectiveness of Alternative Assessment on Academic Achievement, the university of Memphis, U.S.A

Hayajnah, A, D. (2007). Extent of Arabic teachers' use of alternative assessment strategies and the effect of a training program in their practicing these strategies. Unpublished Dissertation, Yarmouk University, Irbid, Jordan.

Jaber, J, A. (2002). Attitudes and modern experiences in assessing the student and the teacher's performance. Cairo, Dar Fikr Arabi, pp: 88-90.

Jameel, S, M. (2009). Effect of using alternative assessment methods in the tenth graders' achievement in national Course in Rosaifa and their attitudes towards them. Unpublished thesis, Hashemite University, Zarqa, Jordan.

Ministry of Education. (2004). Alternative assessment strategies and its tools: theoretical frame, Exams department.

NCTM. (2000). Principles and Standards of school Mathematics. The national council of teachers of mathematics, Inc, p:23

Nurfaradill. Nasri, Siti. Norhidaya, Roslan. Sekuan, Mohammad. Iskauader, Abo Baker. Kasman \& Norputeh. Sharifa, Teachers Perception on Alternative Assessment. Proscenia Social and Behavioral Science, 7(c), 37-42.

Oudah, A, S. (2010b). Measurement and assessment in teaching process, Dar Alamal for publishing and distribution, Irbid, Jordan, pp: 395-430

Oudah, A, S. (2005a). Measurement and assessment in teaching process, Dar Alamal for publishing and distribution, Irbid, Jordan, pp: 519-53.

Popham, W. (2002). What teachers need to know. Journal of educational measurement, 39(1), 85-90. https://doi.org/10.1111/j.1745-3984.2002.tb01136.x

Thorndike, R., \& Hegen, A. (1989). Measurement and assessment in psychology and education, translation. 


\section{Macrothink}

Kilani, A., \& Adas, A. Amman, Center of Books, p:185

Trice, A. (2000). A Handbook of Classroom Assessment. Addison Wesley Longman, Inc.

\section{Copyright Disclaimer}

Copyright for this article is retained by the author(s), with first publication rights granted to the journal.

This is an open-access article distributed under the terms and conditions of the Creative Commons Attribution license (http://creativecommons.org/licenses/by/3.0/). 